\title{
Guanxi in Relationship Marketing of China's Foreign Banks: A Marketing Research to Echo Business Anthropology
}

\author{
Adolphus Yee-Yin Wan \\ Hong Kong Shue Yan University \\ Marco Pui-Lam Ip \\ Hong Kong Shue Yan University
}

\begin{abstract}
This research studies the significance of guanxi in the relationship marketing ("RM") activities of the relationship managers ("Relationship Managers") in China's foreign banks ("CFBs"), in an attempt to help them improve their business performance in China. It is a qualitative research adopting a traditional ethnographic method to collect data through in-depth interviews with ten Relationship Managers of ten CFBs in Shanghai. Non-probability and purposive sampling techniques were applied. The findings confirm, either fully or partially, the research propositions. Such confirmations have led to development of a platform/foundation for further research, particularly in the relationships between marketing research and business anthropology.
\end{abstract}

\section{INTRODUCTION}

In Chinese, guanxi refers to two characters, guan and $x i$, meaning "gate" and "connection", respectively; "one must pass the gate to get connected to networks" (Cheng, 2007, p.81). Guanxi also refers to relationships and social connections based on mutual interests and benefits (Yang, 1994). RM is sourced from Berry (1983, p.25): "attracting, maintaining and ... enhancing customer relationships." Guanxi is different from the Western concept of RM in terms of the order in which transactions and relationships take place and the short-term versus long-term nature of business transactions (Geddie et al., 2002 and 2005; Sin, 1998). The CFBs tend to practice more of Western RM, which is quite different from domestic Chinese banks ("DCBs") which are more focused on practicing the guanxi concept. The application of these two marketing concepts by the two types of banks is believed to have resulted in different business performances. The authors believe the CFBs need to review their RM activities in the light of guanxi.

China began its economic reform in 1978 and has transformed itself from a centrally planned economy to a more market-oriented economy, with a rapidly growing private sector, and has become a major player in the global economy (Kotler, 2010). However, this reform has aroused people's concern about where China stands in the world marketplace today and where it is going (Fisher, 2012). In this research, we have noticed that the reform has accelerated the improvement of China's banking sector in terms of infrastructure, technology and methods to develop business. The performance of the DCBs has been outstanding during these years in both domestic and global markets. Big names such as the Industrial and Commercial Bank of China, Bank of China, China Construction Bank and the Agricultural 
Bank of China are competing successfully against the CFBs. These DCBs owe their outstanding business performance to many factors, such as implicit support from the Chinese government by way of capital injections and business policies. Guanxi is thus implied. In the circumstances, this research also attempts to study whether guanxi is a critical factor responsible for DCBs outperforming the CFBs.

Another important objective of this research is the authors' attempt to establish some relationships between guanxi and business anthropology. Tian (2010) said that anthropology can help business management to improve business performance from product design to marketing strategy; this research views application of guanxi as a marketing strategy for CFBs operating in China's banking industry. Finally, an earlier paper (Wan and $\mathrm{Ng}$, 2013) of the principal author has lent some support to this paper in respect of the research conducted in 2013 to extend further contribution in a multi-disciplinary context relating to marketing research and business anthropology.

\section{LITERATURE REVIEW}

The world views China as the single largest economic force in the new age but anthropologists of China focus on the deeply personal world of various Chinese communities (Noellert, 2011). While CFBs concentrate on use of RM for business development, guanxi is not to be overlooked. The literature review also sheds light on the anthropological perspective and indigenous application of guanxi by the CFBs.

\section{History and Development of RM and Guanxi}

Egan (2004) provided a very clear description of marketing by stages starting from the age of consumer marketing in the 1950s and moving to the 1960s when marketing was characterized by industrial marketing research. Transactional marketing then emerged. In the late 1970s, the focus of attention was the non-profit sector. In the 1980s, the service sector first became prominent. RM emerged in the 1990s originating from industrial marketing to build long-lasting relationships between buyers and suppliers (Perrien and Richard, 1995). Also in the 1990s, RM entered into "matured markets" (Christopher, 1996) and in the $20^{\text {th }}$ century it was labelled by Egan (2004) as the golden age of marketing. Despite rapid development, there is still a relative paucity of empirical research in the RM literature (Kasabov, 2007). The future of RM should focus on moving closer to customers by ensuring total customer integration and virtual corporations.

Guanxi has existed in China's Confucian society for more than two thousand years, dating back to 770470 B.C., the period of Spring and Autumn. At the end of the 1970s when China opened its doors to the outside world, guanxi was investigated in great detail. It was first discussed in Chinese newspapers in 1978 (Yang, 1994, p. 147, cited in Fan, 2002, p. 546). In the West, guanxi first appeared in the 1980s in some popular business writings relating to cultural factors for undertaking business in China (Fan, 2002, pp. 543-544). The future of guanxi is a topic for further research as "even the future trends of guanxi are far from clear" (Ai, 2006, p. 109).

\section{Guanxi: A Theoretical Review of Its Role in Business}

Many authors have defined guanxi in extant literature. Despite numerous definitions having been proposed, there is no universally agreed definition because of its "intricate and pervasive nature" (Chen and Layton, 2003, p. 1218). The role of guanxi is ambiguous. It exists between two persons or families because of blood ties or business acquaintances (Fernandez and Underwood, 2006). Lu (2012) explained the role of guanxi as one of the two cultural norms (the other norm being "renqing") followed in business dealings in China. For business, guanxi is referred to as "a Chinese system of doing business on the basis of personal relationship, which is representative of the way that business is done throughout much of the non-western world" (Lam and Lin, 2003, p. 1437). Recently, guanxi's role in Chinese business has been dramatically affected by international business trends because of foreign investment in China having increased rapidly (Dunfee and Warren, 2001). At the same time, China is undergoing changes because of the influence of Western legal procedures and concepts, resulting in guanxi's role diminishing. Continuation of market liberalization has also diminished the role of guanxi (Wilson and Brennan, 2010). 
This trend is getting accelerated because of advances in information technology, the Internet in particular, resulting in a more open and transparent market system. Thus, reliance on guanxi as a "middleman" is declining. However, given the long history of China, guanxi's important role still prevails, especially when we link guanxi to cultural awareness, to emphasize the concept of guanxi as fundamentally important for understanding cultural interactions in China (Buckley et al., 2006). Cross-cultural interactions between Chinese businesses and their foreign counterparts often occur in the form of marketing communications (Tian and Borges, 2011) and in the process of ensuring customer satisfaction, as in the case of a Chinese restaurant in food service (Tian and Wang, 2010).

To study guanxi in the light of Western theories helps understand RM but it is a complicated proposition, given the different cultures of the East and the West, and the different practices of guanxi and RM in business contexts. Further research in future should link guanxi with various Western concepts and theories, for example, RM, network theory, social exchange theory, resource-based theory and social capital theory.

Morgan and Hunt (1994) provided a classic RM model on the basis of commitment and trust theory claiming that successful RM requires relationship commitment and trust. They further claimed that RM establishes, develops and maintains successful relationship exchange and constitutes a major shift in marketing theory and practice.

Networks aim at obtaining the necessary information and knowledge to optimize organizational performance and provide a framework for gaining resources, knowledge and data. To apply the network theory in practice of guanxi in China, Chen and Chen (2004, cited in Standifird, 2006) claimed that network groups have interpersonal guanxi dyads as their fundamental units. Networks form an important ingredient of guanxi-based business practices (Standifird, 2006). Guanxi is a form of social network theory (Hammond and Glenn, 2004).

Social exchange pertains to the relationship between unspecified obligations and expectations of returns in the future, in return for contributions made (Blau, 1964). Guanxi involves social exchange in the sense that it is an informal, complicated and non-transparent process, involving a series of interactions that generate obligations, reciprocity and exchange (Emerson, 1976, cited in Cropanzano and Mitchell, 2005). In relation to social exchange is the concept of social capital which is defined as goodwill resulting from the structure of social relations (Warren et al., 2004). Social capital theory has a close association with guanxi. Guanxi can be considered as a type of social capital developed between two persons via a process of reciprocal exchange (Fan, 2002, cited in Standifird, 2006).

Resource-based theory helps analyse a company's strengths and weaknesses in terms of financial, physical, human and organizational resources. Discussions of the relationship between guanxi and the resource-based theory or guanxi as a resource are abundant in extant literature. Butterfield (1983) associated guanxi with social investment, which is an important source for people to access help or support. Su et al. (2003) stated that guanxi connects people in the form of a resource coalition to facilitate the sharing of resources between business partners. Some studies have drawn upon resource-based theory by associating guanxi with an organizational resource and the capability to improve a firm's performance and competitive advantage (Xin and Pearce, 1996; Tsang, 1998; Braendle et al., 2005). Therefore, guanxi can be classified as a resource (Tsang, 1998).

In conclusion, guanxi acts as a stimulus to cultural interactions and is becoming increasingly more important for multinational companies in China (Yang, 2011). The CFBs need to be aware of the role of guanxi in the context of the Western theories and concepts and use it to establish better institutional connections with local stakeholders, including customers, employees, local partners and government officials. They should also acknowledge that it is essential to understand and practice guanxi if they want to be successful in China.

\section{Guanxi in the Practice of RM}

Focus of this literature review is incorporation of guanxi in the practice of RM. Guanxi is practiced via personal relationships, as opposed to the Western practice of RM which focuses on specification and enforcement of contracts (Davies et al., 1995). Gronroos (1996, cited in Arias, 1998) viewed guanxi 
essentially as a Chinese cultural construct but RM as a service or management of the service delivery process for doing business. Good guanxi reinforces RM and ensures its success whereas bad guanxi spoils RM and in turn terminates the transaction (Wong, 2007). Guanxi differs from the practice of RM in three aspects: (a) RM focuses on a purposefully-built relationship but guanxi emphasizes family ties; (b) principles of Confucianism or one's family and social roles are found in guanxi; and (c) guanxi favors personal bonds while RM facilitates inter-group or inter-organization relationships (Alston, 1989, cited in Fock and Woo, 1998). These differences affect the practice of guanxi in RM by managers, for example, the formation of pricing strategies and the process of relationship building and business negotiations (Gilbert and Tsao, 2000). Other examples of practicing guanxi in RM activities are: the guanxi initiator (1) shows honesty, introspection and reliability; (2) gives gifts; (3) keeps contact with guanxi members; (4) spends time on social activities such as dining and drinking; (5) frequently provides help and offers free favors to parties in the network; and (6) pays favors back as a means of keeping the guanxi network running (Ai, 2006). The operationalization of guanxi is very difficult because guanxi is very complex and goes beyond the economic context (Arias, 1998).

\section{Guanxi and Business Performance}

Some researchers have reviewed the relationship between guanxi and business performance, measured in terms of sales growth, customer retention, return on investment and market share (Sin et al., 2002; Tse et al., 2004). In respect of the relationship between guanxi and business performance, Zhang and Zhang (2006) provided a detailed explanation that there is no consensus on the positive effect of guanxi on business performance. Fan (2002) maintained that the benefits of guanxi for economic and organizational efficiency may be exaggerated. Other investigators have claimed that guanxi has no effect, or may even have a negative effect, on a firm and its performance (Braendle et al., 2005).

The positive view of the relationship between guanxi and business performance is reflected in Luo and Chen (1997) who claimed that a firm can enhance its performance by benefiting from a guanxi network and this network constitutes a firm's core competency and distinctive competitive advantage that can lead to high performance. This reinforces the claims of Su et al. (2003) that high-guanxi firms have outperformed low-guanxi firms in terms of business efficiency, sustainability of competitive advantage, access to scarce resources and enhancement of long-term survival and growth. Results of a survey by Wang et al. (2011) relating to the effects of organizational support and guanxi on salespersons' performance indicate that salespersons' guanxi with customers have a positive influence on their job performance. However, in spite of the positive comments of the authors, guanxi does not trump everything.

\section{RESEARCH PROBLEM, PROPOSITIONS AND CONTRIBUTIONS}

\section{Research Problem}

The purpose of this research is to study guanxi for the application to RM of the CFBs. The literature review indicates a substantial volume of literature on Western RM theories and guanxi in general but no prior studies seem to have investigated guanxi in China's banking industry, particularly its practice by the CFBs. Also, there are no surveys on how important the guanxi practice is in RM activities of the CFBs and discussions of the relationship between guanxi and bank performance through the implementation of a CRM system with guanxi elements. Therefore, the problem of this research is defined as:

How significant is the Chinese concept of guanxi in RM activities of the CFBs in China's banking industry?

The following are the related research questions, each of which has been formulated through literature review, pilot interviews with experienced bank marketing executives and the bank marketing experience of the principal researcher performing this research: 
Research Question 1: How do different views on guanxi and its practice affect marketing activities and operations of the CFBs?

Guanxi is a Chinese form of RM. It affects the marketing activities and operations of the CFBs in terms of customer relationship building, maintenance and development. The CFBs are using Western RM concepts in business development and have encountered difficulties in practicing Chinese guanxi along with the Western RM concept due to differences between culture and business practices in China and Western countries. However, it is commonly accepted that guanxi does affect marketing and operations of the CFBs. The first research question is: How do different views on guanxi and its practice affect marketing activities and operations of the CFBs?

Relationship Managers employed in banks in China are believed to hold different views of guanxi. The success of a bank's RM in China depends on the degree to which the relationships of customers and banks are merged to form a cooperative unit or a merged partner. In guanxi marketing, a merged partner relationship between the company and customers is established. However, in RM, the customers are only treated as a subset of the company (Sin, 1998). It therefore leads to the proposition that:

P1a: Different views on guanxi in association with RM affect marketing activities and operations of the CFBs.

Assuming the above proposition is confirmed, it is necessary to study the effect of practicing of guanxi by Relationship Managers of the CFBs by raising the following proposition:

P1b: Whether guanxi can be efficiently practiced and operationalized for effective RM activities and operations of the CFBs.

Research Question 2: Does guanxi affect business performance of the CFBs?

As discussed in the Introduction section, the major DCBs are performing very well, as is evident from the growth of global branch networks, outstanding business performance and aggressiveness in recent mergers and acquisitions in the domestic as well as global capital markets. People tend to believe that one of the critical success factors is their guanxi networking activities which are not practiced by the CFBs. Guanxi continues to play a major role and is a determinant of business performance and long-term business success (Davies et al., 1995; Yang, 1994 and 2002; Millington et al., 2005) for Chinese organizations. However, some authors (Zhang and Zhang, 2006; Dunfee and Warren, 2001) have claimed that there is no consensus and benefits of guanxi are over-stated (Fan, 2002). The second research question is then derived: Does guanxi affect business performance of the CFBs? A positive answer to the above question consequently leads to the following proposition:

P2: DCBs with high guanxi outperform CFBs with low guanxi and the lack of guanxi is a reason that undermines business performance of the CFBs.

\section{Contributions}

Answers to the research issues and questions are derived from the findings presented in Table 1, which also suggest theoretical and practical contributions of this research. In terms of theoretical contributions, research results confirm the propositions developed through Western theories as discussed in the Literature Review section. This suggests that wider utilization of Chinese concepts/theories like guanxi should exist in some organizations where Western culture is prevailing, e.g., the CFBs. For the practical value of this research, firstly, guanxi is a very complicated concept in the context of banking industry due to its highly sensitive nature, particularly with regard to corruption and bribery which are strictly forbidden in banking. The research suggests incorporation of guanxi into RM activities of the CFBs in the future. This is a pioneering attempt in the banking industry and no previous research work 
has examined guanxi in CFBs of China's banking industry, notwithstanding the numerous studies regarding the importance of guanxi in non-banking foreign firms. Secondly, given that guanxi is a typical component of Chinese culture, this research can only be practically applied in countries where guanxi prevails. However, it provides some insights into foreign cultures, which apply RM in business. Thirdly, the findings provide bank managements and Relationship Managers with practical marketing guidelines.

\section{RESEARCH METHODOLOGY AND DESIGN}

\section{Research Design and Approach}

This is a social research project and an experimental/exploratory design was chosen to meet the research criteria. Hitherto little has been known about, and no information is available on, whether guanxi can be incorporated into RM activities of the CFBs. Therefore, an exploratory study was undertaken to better comprehend the research problem. A cross-sectional study was also carried out because data was gathered just once over a period of one week, through interviews with Relationship Managers of selected foreign banks in Shanghai, in order to meet the research objective. The study thus has a "one-shot" characteristic; a longitudinal study could not be conducted due to time and cost constraints.

\section{Sample and Sampling Technique}

The samples cover Relationship Managers of ten CFBs. The selected banks are purely commercial and are located in Shanghai. These banks are important in terms of size, exposure and business experience in China, as well as international capital markets, as listed in the "China Financial Services Directory" and the "Bankers Almanac". Their national diversity and long-term business commitment (e.g. ten years or more) in China were also inclusion criteria for sample selection. The city of Shanghai was chosen because it is a major city where many foreign banks have established their China headquarters.

One participant from each bank was invited to attend the interview, making a total of ten Relationship Managers. This sample size is considered acceptable as it represents around $33 \%$ of the foreign bank population. In accordance with the "China Financial Services Directory", there are approximately 30 foreign commercial banks with branch status in China.

Sample constituents from the selected CFBs are marketing executives working as relationship managers, officers or heads of marketing departments (e.g. Corporate Banking, Business Banking, Private Banking, Retail Banking, Customer Services, or Trade Finance) who have direct and face-to-face contact with customers in the course of their daily marketing activities. The sampling was confined to such specific people (i.e. Relationship Managers) who could provide the desired information on guanxi/RM. With respect to the sampling technique, this research adopts purposive sampling, which matches the topic, which is social and behavioral and which is related to the characteristics of human nature.

\section{Data Collection Methods}

Data was collected by using a qualitative method because guanxi is a complex issue involving social, behavioral and human elements. Guanxi exists within the complex environment of China's banking sector and it is a phenomenon that cannot be addressed or measured quantitatively. In this respect, semistructured, open-ended, individual in-depth and face-to-face interviewing was used. This data collection method is considered ideal because the process involves significant prompting, probing, collecting additional data, asking additional questions, establishing rapport and motivating participants during the data collection process. Interviews were conducted in the interviewees' offices or at any sites convenient to them. Participants had a working knowledge of English. Interviews were conducted in both Putonghua and English and Cantonese was also used in some cases where the participants were originally from Hong Kong. Note-taking rather than voice-recording was used due to the need for confidentiality. Subsequent telephone follow-ups with the interviewees were made to clarify any doubts about information collected in the interviews via the note-taking method. 


\section{Data Analysis}

Data was analysed mainly through qualitative approaches such as secondary data analysis, content analysis, categorization, interpretation, quotations and narrative forms to see if the research questions were supported or the research objectives were substantiated.

For the first part of this research, secondary data analysis and content analysis methods were used. The researchers analyzed the data regarding guanxi gathered from previous surveys and published research, which were used as secondary data for the purpose of studying guanxi and RM in general. Then, the researchers supplemented the secondary data with primary data, or judgements obtained through interviewing the Relationship Managers, to fully address the research problem.

In the data analysis process, the researchers also undertook an initial analysis of interviews and field notes. This was followed by constant comparison of emerging themes and categorization of core codes into two pre-planned units of: (a) Views and practice of guanxi in RM activities and operations of CFBs; (b) Guanxi and business performance of CFBs. The researchers then deepened their analysis by comparing their findings with the established concept of guanxi as described in extant literature. Finally, the analysis was compiled into written forms by means of narrative analysis, interpretation, quotation and data display.

Data in this research is presented in accordance with methods suggested by Sobh and Perry (2006). Firstly, in spite of some empirical experiences obtained from the participants, the data eschewed numbers and concentrated on qualitative approaches like interpretation, narrative analysis, content analysis and secondary analysis. Secondly, every observation from the interviews had an explanation of why the observed event had occurred. This explanation was linked to what the participant said and is supported by representative quotations, thus providing the in-depth understanding that the researchers sought. Finally, data analysis computer software was not used because the sample size of this research is small. This omission was necessary in light of cost and time factors.

For verifying the validity of the research findings, the researchers could not use scientific and quantitative methods to measure guanxi. In addition, validation was not feasible at this stage as this is a continuous process requiring follow-ups through the qualitative approach of trustworthiness in terms of credibility, transferability, dependability and verifiability.

\section{ANALYSIS OF RESEARCH ISSUES/PROPOSITIONS}

\section{Views and Practice of Guanxi in the RM Activities and Operations of the CFBs}

Finding 1: How guanxi affects marketing activities and operations of the CFBs depends on the understanding of the Relationship Managers of: (1) the views of guanxi in association with RM; and

(2) whether guanxi can be efficiently practiced and operationalized for effective RM activities and operations of the CFBs.

\section{Views of Guanxi in the CFBs}

The above finding outlines the importance of guanxi for a long-term relationship between a bank and a customer. One participant said: "Guanxi should be practiced by the CFBs because: (1) the CFBs focus on the market in China; and (2) banking is a tertiary industry and needs to rely more on guanxi." However, another participant emphasized the impracticability of guanxi in his RM activities due to the difficulties in transplantation of the Western RM concept into the Chinese guanxi concept or vice versa:

"The CFBs hold the Western RM concept in their business development and banking operations. This concept is quite different from the guanxi concept. It is difficult for the CFBs to transplant the RM concept in guanxi because of the different cultures and economic and social environments."

The findings indicate participants' perceptions of guanxi's practice in a foreign culture vary, in terms of its effects on their marketing and operational functions in the areas of (a) customer relationships; (b) networks and communications; (c) staff-customer relationships; (d) accounts management; (e) business 
ethics; and (f) bank operations. Therefore, Proposition 1a (P1a) "Different views on guanxi in association with RM affect marketing activities and operations of the CFBs" is confirmed.

\section{Guanxi in RM and Operations of the CFBs}

Guanxi in Customer Relationships. 90\% of the participants claimed that the DCBs are more inclined to practice guanxi and they are more skilful in building guanxi. The following comment was made:

"Foreign banks often lack long-term relationships with Chinese customers. Relationships between the CFBs and enterprises are mainly built on corporate cooperation, meaning a corporate guanxi exists. Under this guanxi, the customer and the bank emphasize procedures and policies and there is a certain degree of distance between the two parties. However, in the DCBs, relationships between the banks and customers are multi-dimensional and corporate guanxi is not so significant. Very often, the Relationship Managers spend lot of time developing personal guanxi with decision-makers of their customers, for example, engaging in entertainment, adopting some hobbies of common interests and even helping family members of the customers in order to build up intimacy."

Guanxi facilitates customer relationships and is extensively used in RM activities by banks in China. The findings show that CFBs acknowledge the important applications and usefulness of guanxi for maintaining a stable client base, enhancing satisfaction of customers, facilitating new customer referrals and advocacy, operationalizing customer commitment and trust in customer relationships, reviving deteriorating customer relationships and developing bank image and customer awareness of the bank. All of these RM activities can be facilitated by guanxi. In addition, guanxi can also help smooth bureaucratic processes, provide access to business opportunities from state-owned enterprises and secure support from relevant government bodies.

Eighty percent of the participants supported guanxi as a means to attract more clients but their managements have not proactively committed to implementation of the guanxi concept in RM activities. They believe that creating a competitive advantage in a bank based on excellent services is more important than guanxi.

Guanxi in Networks and Communications. Findings show that $70 \%$ of the participants believe they have good guanxi with their customers because of excellent and frequent communications. Fifty percent of the participants were neutral to the statement that guanxi can assist in solving problems and providing solutions for their customers. Eighty percent of participants did not agree that their banks focused on guanxi networking as part of their business strategy. However, $70 \%$ participants believed that guanxi could function in the information network of their banks, and banks with wide "guanxi" and relationship networks performed better than those with little or no relationships with Chinese customers.

Guanxi with Staff-Customer Relationships. Findings indicate that support for guanxi in staff-customer relationships is confirmed as $80 \%$ support guanxi as an effective tool to develop and foster relationships between staff and customers. Guanxi is maintained through staff-customer trust by solving problems, rectifying errors and responding promptly to customers, and by providing expertise that gives customers the perception of credibility.

Guanxi in Accounts Management. The findings also indicate that on average Relationship Managers allocate $70 \%$ of their time to accounts' management. Relationship Managers spend substantial time on relationship cultivation, including clients and site visits, establishment of mutual understanding, problem investigation and solution, customer entertainment and social gatherings (e.g. lunch, dinner, playing golf and social event participation). Accounts administration and other activities relate to internal administrative functions, to support RM. These activities take up around $30 \%$ of the time of the Relationship Managers.

Guanxi as Ethics in Bank Operations. Eighty percent of the participants agreed that guanxi can take many forms, such as gift-giving and reciprocity, i.e. it cannot be simply based on money and is considered legal in Chinese culture for building relationships. It is not viewed as bribery. There is no need to feel uneasy or uncomfortable about guanxi. Finally, $90 \%$ of the participants believe that guanxi with high 
ranking government officials is still important for doing business in China. They then added one comment that corruption and bribery in B2G guanxi still prevails in China.

Guanxi in Banks' Operations. Findings indicate 100\% of the participants support high quality services as their banks' strategies to sustain long-term relationships and proper guanxi. This also applies to the pricing strategy in which $80 \%$ of the participants indicated guanxi can reduce a customer's price sensitivity because of trust. One hundred percent of the participants claimed that a closer relationship is needed due to technological innovation and increased automation in banks' operations, business and services, thus fostering "emotionless" services found in virtual banking or the virtual marketing/virtual corporation. Finally, participants agree that guanxi can streamline operations but it depends on the allocation of financial resources to support guanxi management.

In conclusion, guanxi has a significant effect on RM activities and banks' operations as discussed in the above research findings and therefore Proposition $2 \mathrm{~b}(\mathrm{P} 2 \mathrm{~b})$ "Whether guanxi can be efficiently practiced and operationalized for effective RM activities and operations of the CFBs" is confirmed.

\section{Guanxi and Business Performance of CFBs}

Finding 2: Guanxi has been extensively practiced by the DCBs but not the CFBs. People are led to believe that guanxi is one of the critical success factors for the DCBs because of its major role as a determinant of good business performance from a long-term business perspective in China. Notwithstanding that the findings make it difficult to draw a consensus on the notion that guanxi does affect performance of the CFBs, they indicate that the CFBs should practice guanxi in their RM activities via the development of a guanxi-based CRM system in order to improve their performance in China.

Eighty percent of the participants indicated that they had heard of CRM systems involving people, processes and information technology, though only $50 \%$ of the participants have installed (or will install) a CRM system. On the other hand, $70 \%$ of the participants expressed the opinion that the development of a CRM system can help operate and enhance guanxi in RM and assist in the development of a guanxi strategy. A CFB participant commented as below:

"A CRM system can monitor guanxi progress with the customers ... Data storage can reveal and update the happenings and status of each customer for guanxi purposes. This can facilitate better operation of guanxi with the customers."

Finally, eight participants ( $80 \%$ ) proffered no ideas on how to develop a CRM system, should they be asked to do so. This reveals a problem in installation of systems without incorporation of guanxi elements and the need to make the CRM system more guanxi-oriented.

The findings also shed light on measurement of guanxi in respect of performance of the CFBs. In the survey, the focus of the interviews was on discussion of guanxi against measurement factors such as customers, relationship quality, bank and account managers, staff commitment and loyalty, profitability and business performance.

Customers. One hundred percent of the participants claimed that "customers" are an important factor and guanxi may be measured via loyalty and satisfaction, new customer acquisitions and referrals, amount of business generated and the amount of profit from each customer.

Relationship Quality. Nine participants (90\%) emphasized the importance of relationship quality as a factor to measure guanxi. Good guanxi with customers and senior managers of their companies ensures high quality relationships and thus secures good profit from the account. Guanxi also promotes relationship quality via provision of standard products and services, enhancement and sustaining of competitive quality of services.

Banks and Account Managers. Seventy percent of the participants claimed that guanxi helps banks capture customers. Measurement of guanxi in terms of "banks" depends on the number of banks with which the customers have maintained accounts and the share in banking facilities obtained by the 
customers. Measurement of guanxi in terms of "account managers" is determined by business volume and profits generated from individual customers.

Staff commitment and loyalty. One participant said: "It is critical to judge the staff's commitment towards guanxi." Another participant claimed: "Staff commitment and loyalty ensure that the bank's interests are not jeopardized by the personal guanxi of the relationship manager with his/her customers."

Profitability/Business performance. Fifty percent of the participants did not agree that guanxi has little influence on their banks' returns on sales. Seventy percent of the participants claimed that their banks could realize business on a broader scale if they made use of guanxi; yet, two participants did not agree with this statement despite having assigned a relatively high weight to guanxi. They thought that today's customers were very demanding in terms of actual benefits (e.g. a broader scale of services) from their banks and that guanxi alone cannot work. Participants also emphasized diversified and quality products and services to customers, besides guanxi, as a critical success factor for doing business in China. Therefore, they remained neutral concerning the statement that most bank business is generated through guanxi and, without guanxi, banks would find it difficult to survive and grow in China.

However, a large proportion of participants (70\%) agreed that banks with wide guanxi usage often perform better than those with little or no relationship with the Chinese and guanxi is useful in order to maintain a competitive advantage. This applies to the DCBs also (as claimed by the participants). Despite $70 \%$ of the participants claiming a positive relationship between guanxi and banks' competitive advantages, they were not keen to practice guanxi in their business development and, therefore, business performance might have been adversely affected. This is reinforced by the following comments of two participants:

"Profitability/business performance is the ultimate objective of good guanxi which is true for both banks and enterprises."

"Effective guanxi can contribute to profit and good business performance of the banks in the future."

The above comments are suggestive of the importance of guanxi for business performance of banks in China. However, in the interviews, a number of participants claimed that guanxi itself cannot guarantee good business performance and, therefore, banks should gain their own competitive advantages and not simply rely on good guanxi with customers. Proposition P2 (P2) "The DCBs with high guanxi outperform the CFBs with low guanxi, and the lack of guanxi is a reason that undermines the business performance of the $C F B s$ " is partially confirmed.

\section{RESULTS AND DISCUSSION}

The findings of this research are consistent with mainstream previous studies of the general concepts of guanxi in the China context. Table 1 and Table 2, which are self-developed for this research, summarize findings against research questions and propositions by addressing the research problem. 
TABLE 1

SUMMARY OF FINDINGS AGAINST EACH RESEARCH QUESTION

\begin{tabular}{|c|l|}
\hline Research issue/question & \multicolumn{1}{c|}{ Findings } \\
\hline $\begin{array}{l}\text { RQ1: How would different } \\
\text { views on guanxi and its } \\
\text { practice affect marketing } \\
\text { activities and operations } \\
\text { of the CFBs? }\end{array}$ & $\begin{array}{l}\text { How guanxi affects marketing and operations of the CFBs depends on } \\
\text { the understanding of the Relationship Managers of (1) the views on } \\
\text { guanxi in association with RM; and (2) whether guanxi can be } \\
\text { efficiently practiced and operationalized for effective RM activities and } \\
\text { operations of the CFBs. }\end{array}$ \\
\hline $\begin{array}{l}\text { RQ2: Does guanxi affect } \\
\text { business performance of } \\
\text { the CFBs? }\end{array}$ & $\begin{array}{l}\text { It is difficult to conclude from the findings whether guanxi does or } \\
\text { does not affect business performance. However, the CFBs should } \\
\text { enhance their competitive capabilities and advantages in China market. } \\
\text { They should develop a guanxi-based CRM system in order to improve } \\
\text { their business performance. Future research in this aspect is required } \\
\text { because of the undeniable importance of guanxi based on the findings } \\
\text { of this research. }\end{array}$ \\
\hline
\end{tabular}

Proposition P1 to P2 are intended to answer the two questions as described in Table 1.

TABLE 2

RESULTS OF FINDINGS FOR EACH RESEARCH PROPOSITION

\begin{tabular}{|c|c|}
\hline \multicolumn{1}{|c|}{ Description of Research Issues/Propositions } & $\begin{array}{c}\text { Results of } \\
\text { Findings }\end{array}$ \\
\hline $\begin{array}{l}\text { P1a: Different views on guanxi in association with RM affect marketing activities and } \\
\text { operations of the CFBs. }\end{array}$ & Confirmed \\
\hline $\begin{array}{l}\text { P1b: Whether guanxi can be efficiently practiced and operationalized affects RM } \\
\text { activities and operations of the CFBs. }\end{array}$ & Confirmed \\
\hline $\begin{array}{l}\text { P2: DCBs with high guanxi outperform the CFBs with low guanxi and the lack of } \\
\text { guanxi is a reason that undermines business performance of CFBs. }\end{array}$ & $\begin{array}{c}\text { Partially } \\
\text { confirmed }\end{array}$ \\
\hline
\end{tabular}

The findings reported in Tables 1 and 2 lead to two main themes which help achieve an understanding of the research objective in relation to the study of guanxi's significance to the CFBs. Finally, the findings provide a platform and foundation for further investigations in the new areas identified in this research.

\section{Views and Guanxi in the RM Practice of CFBs}

Relationships between guanxi and activities of the Relationship Managers in the CFBs are established through confirmation of $\mathrm{P} 1 \mathrm{a}$ and $\mathrm{P} 1 \mathrm{~b}$. The findings confirm that guanxi should be practiced by the CFBs regardless of the Western RM concepts followed by the Relationship Managers. However, there are difficulties in transplanting the RM concept from Western countries (Palmer, 1995) into banking practices in China, and in integrating the guanxi concept with RM activities of the CFBs due to differences in culture and business practices. Further, the findings demonstrate that guanxi bears a strong relationship with marketing and operations of banks in China, e.g., customer relationships, products and services, pricing strategies, networking and communications, staff-customer relationships, accounts management and ethical issues. The CFBs are not exceptions. These findings establish the importance of guanxi as a new area for future research.

The findings also focus on the importance of how CFBs coordinate with their head offices for design of customer-oriented service systems (e.g. CRM system) with integrated guanxi elements. CRM is viewed by many Relationship Managers of the CFBs as a marketing process to foster customer relationships through a so-called CRM system, by delivering superior customer value and satisfaction. 


\section{Guanxi and Business Performance of CFBs}

In respect of the relationship between guanxi and business performance of the banks, particularly the CFBs in China, findings indicate a dangling answer to whether guanxi influences returns on sales. Relationship Managers consider profitability and business performance as the ultimate objectives of good guanxi for banks and other enterprises in China. This confirms the claims of Davies et al., (1995), Millington et al. (2005) and Yang (1994) that guanxi plays a major role in China and East Asia. However, guanxi itself cannot guarantee good business performance. This finding confirms the comments of Braendle et al. (2005) and $\mathrm{Li}$ and Athuahene-Gima (2001) that guanxi has no effect or even a negative effect on a firm and its performance. The findings also confirm the claim of Zhang and Zhang (2006) that there is no consensus on the positive effect of guanxi in relation to business performance. The most important factor for the success of banks in China is competitive capabilities of the Relationship Managers and the competitive advantages of the banks. Therefore, the findings emphasize the provision of diversified and quality products and services, offers of attractive pricing and tailor-made services to customers as success factors rather than sole reliance on guanxi. Other non-financial factors such as relationship quality, staff commitments and loyalty, reward and staff motivation and business ethics, etc. are also critical factors that affect the profitability and business of the banks.

\section{IMPLICATIONS OF THE RESEARCH}

This research provides two types of implications: (1) theoretical implications; and (2) practical implications. For theoretical implications, first, there is a close relationship between guanxi and some Western theories as outlined in the Literature Review section. It is then feasible for the CFBs to practice guanxi along with the Western management concept of RM. Second, there is a need for the future development of guanxi-bank related theories. The findings indicate a lack of such literature, for example: (a) integration of guanxi with RM for the CFBs; and (b) relationships between guanxi and marketing/operations of the CFBs. It is difficult to link guanxi to banks' marketing practices in China in the absence of sufficient theories and literature in the field. In terms of practical implications, the general application of guanxi in conjunction with RM activities of CFBs, and the formulation of a guanxi-RM conceptual framework for the use of the CFBs are two practical implications and new areas for future research.

\section{LIMITATIONS OF THE RESEARCH}

The researchers encountered a number of limitations that were beyond control. They are (1) limitations of research methodology; and (2) limitations of conducting research in China. While such limitations are acknowledged, they do not detract from the significance of the findings. Instead, they have provided platforms for future research.

The first limitation of research methodology was that the selection of Shanghai as the location posed time and cost constraints. Secondly, "one-shot" interviews used in this research were not sufficient to produce full and rich descriptions of the findings.

With respect to limitations of conducting research in China, data collection activities in this research were influenced by a number of practical considerations including the lack of up-to-date, comparable and complete information from industrial directories in China, and a strong disinclination of Mainland China people to reveal information about their views on guanxi to outsiders. The latter is a sensitive issue for bankers, as far as their view of guanxi is concerned.

\section{DISCUSSION OF THE RESEARCH IN THE FIELD OF BUSINESS ANTHROPOLOGY}

This section is divided into two parts: (1) Business anthropology as a sub-discipline of anthropology; and (2) Relationships of the research with business anthropology. The first part provides a general review of anthropology and business anthropology in respect of its development, growth, importance and future. 
The second part focuses on the discussion of: (a) The rise of business anthropology in China; (b) Ethnography as a research method; (c) Guanxi in the corporate and cross-cultural context; and (4) Business performance of CFBs versus business anthropology. All of these issues bear a close relationship between this research and business anthropology.

\section{Business Anthropology as a Sub-discipline of Anthropology}

\section{Anthropology and Its Development}

Anthropology is a discipline for over the last hundred years or so. It has developed a wide array of qualitative techniques for understanding people and their behaviours. Despite it being a discipline and methodology employed by business researchers for a short period of time, anthropology has a long history within business research as in the case of the seminal "silent language" approach introduced by Hall $(1959,1960)$. Other examples are the classic anthropological methods of research such as ethnography, observation and interviewing that have proved to be appropriate for business research (Walle, 2000, 2002; Jordan, 2002, cited in Tian, 2009).

Anthropology is defined by Tian et al. $(2013$, p. 24) as "a social science that studies the social environment in which people live and the impact of this social environment on feelings, attitudes, behaviours, and so on." Tian et al. (2013, p. 27) further claimed that "anthropology is the study of human beings as both natural and social creatures, from the times of our pre-human ancestors' earliest appearance on earth to contemporary times."

There are four traditional fields of anthropology: (1) cultural anthropology (or "sociocultural anthropology); (2) archaeology; (3) physical (or "biological) anthropology; and (4) anthropological linguistics. The above classification is based on the interest of anthropologists in studying anything in connection with the existence, development, appearance, behaviour and beliefs of human beings and "each of these four fields focuses on a different aspect of human life" (Tian et al., 2013, p. 28). These traditional fields of anthropology primarily focus on creating theoretical models relating to its units of analysis and the anthropologists usually specialize in one particular field in its entirety.

The practical application of any of these four traditional fields may be designated as applied anthropology, which is regarded by some scholars as a fifth sub-discipline of anthropology. Practicing applied anthropologists do not simply study the nature of problems, but focus on the solutions to the problems by applying anthropological data, theories, models and methods to identify, evaluate and solve contemporary problems in organizations or social enterprises. They make contributions to business, government, health, education and human services domains. They use ethnography and participant observation as their primary research tools.

\section{Growth in Business Anthropology}

Walle (2003, cited in Tian et al., 2013, p.11) stated that the glimmerings of business anthropology first emerged in the 1930s in association with "human relations school". It then exerted a powerful influence on an entire generation. During the 1960s and 1970s, the use of business anthropology declined. The term of "business anthropology" became more popular and widely used in the 1980s and it has recently begun to be used more generically in the application of anthropology to business-oriented problems. Currently, anthropologists increasingly serve as business researchers, and their cultural sensitivity of the qualitative methods of anthropology is making organizations increasingly aware of business anthropology. Their contributions are much needed and valued by decision-makers of different organizations.

To further understand business anthropology, researchers should throw light on what "business" means. Tian et al. (2013, p.14) opined that "business" is "an entity that brings together time, effort and capital in order to produce a profit." He further claimed that the term "business" suggests three usage as (1) a particular company or corporation (singular usage); (2) a particular market sector (generalized usage); and (3) all activities by the community of suppliers of goods and services (broadest usage). However, Dr. Robert Tian, a business anthropologist trained in the USA, commented that the exact definition and philosophy of business is a matter of debate. 
Scholars tend to associate business anthropology with applied anthropology in that the research sometimes may not be referred to as academic research but fall within the applied field as in the example of business anthropology which serve as "applied" anthropology. Tian et al. (2013, p. 34) alleged that "the use of anthropological ideas and methods to achieve practical goals primarily in the private, for-profit sector is termed business anthropology or, alternatively, corporate anthropology". In his article "Editorial Comment: The Rise of Business Anthropology in China", he straightforwardly claimed business anthropology as a sub-discipline of applied anthropology to apply anthropological theories and methods to explore and solve problems in the real business world by studying how to improve business efficiency and work processes through observing how people perform in their workplace (Tian, 2013a). Van Rij (1996, p. 19) claimed that "business anthropology is a new way of thinking about the challenge of keeping up with global change." He further claimed that business anthropology provides a set of advanced concepts for market strategy and can help firms to leverage knowledge of customer perceptions of the environment to enhance competitive strategy in transnational markets. Chapman (1997) viewed anthropology to be generally true on business and management studies spanning large areas of marketing, finance and accounting, human resource management and production and operations management. According to Moeran (2005), anthropology offers explanations about how people and organizations come together and function.

\section{Importance of Business Anthropology}

The importance of business anthropology can be viewed through its role and functions in which business anthropologists have been widely recognized and they are able to help solve most business problems in the real world with their unique contributions (Jordan, 2010). Business anthropologists have been hired to investigate sources of trouble and to suggest remedies. They can also help mediate and open communication between groups of workers and managements (Reice, 1993). In practice, they play very different roles in companies in the above mentioned areas. Specifically, the importance of business anthropology has been concluded by Jordan (2010) in three fields of (1) organizational anthropology meaning the study of complex organizations to include their cultures, work processes and change directives; (2) anthropology of marketing and consumer behaviour; and (3) design anthropology to include product and service design. The other anthropologist, Dr. Robert Tian, also added the fourth and the fifth field. The fourth field is termed as competitive intelligence and knowledge management to focus on the study of unique methods by anthropologists to be used in competitive intelligence and knowledge management (Tian, 2009). The fifth field is termed as anthropology of international and cross-cultural business (Ferraro, 2006; Lillis and Tian, 2009).

In conclusion, the importance of business anthropology is echoed by its characteristic as a "practical oriented scholastic field" in which anthropologists and scholars from other disciplines can apply anthropological theories, methods and skills to identify and solve all kinds of business related problems in various business environments, domestically or globally (Tian et al., 2013, p. 35).

\section{Future of Business Anthropology}

The future of business anthropology is challenged by advanced technologies along with globalization of the world's economic system. For example, organizational changes occur due to mergers of companies on a global basis (Tian, 2013a) and multinational corporations need to understand the cultures of many countries in which they operate (Jordan, 2010). Besides, cross-cultural cooperation between geographically-dispersed teams of multinational companies has created another challenge for such companies to procure business anthropologic knowledge and skills to become successful in their business commitments. Therefore, anthropologists opine that when they discuss the future of business anthropology, they must think in terms of global political economy, local demographic trends, prevailing cultural preferences and the social and ethnic backgrounds of consumers; they should also think how they might fit into the discipline of business anthropology to continue as a practice-oriented entity (Tian, 2011). 


\section{Relationships of the Research with Business Anthropology}

\section{The Rise of Business Anthropology in China}

China has undergone tremendous economic and social change since it launched economic reform in the late 1970s. It gradually changed from its closed and centralized economic planning system into a marketoriented economy. In 2010, China took over Japan and became the second-largest economy in the world after the US (Source: Central Intelligence Agency, 2012). It has become a locomotive of the world economy. However, Chinese businessmen have faced many problems in foreign countries due to China's lack of research on globalized markets, business counterparts and cultural factors of other countries. Now Chinese business leaders know that in order to survive, they must have a better understanding of the international market environments from a cross-cultural perspective (Paliwoda and Ryans, 2008; Yu et al., 2006, cited in Tian, 2013a). In fact, as claimed by Harrell (2001), since the beginning of China's reform and opening policy in 1978, anthropological studies of China have revived and so has anthropology as a discipline because Chinese anthropologists have become part of the world community of anthropologists.

Given the importance of understanding the diverse cultures in the global markets as well as the business practices of foreign counterparts, business anthropology was introduced and promoted in Chinese universities during a critical period of China's economic development. Since 2005, Dr. Robert Tian has run seminars on business anthropology at Peking University, Minzu University and Fudan University in China. He was also appointed as a foreign expert professor to offer business anthropology courses to both graduate and undergraduate students at the Business School of Shantou University in 2011. He organized two international conferences on business anthropology in Beijing and Shanghai in 2012 and 2013 and a third in Hunan of China in May 2014. In September 2012, two groups of applied anthropologists ran two sessions at the national conference of anthropology in Lanzhou, Gansu Province. All of these events show the awareness of business anthropology in China and that "business anthropology has a bright future in China and will soon boom in China as an academic discipline as China's social and economic development continues at a fast speed" (Tian, 2013a).

The research titled "The Role of Guanxi in China's Foreign Banks" was conducted in Shanghai, China in 2013. As research on business anthropology expanded, findings were deeply affected by the need for the development of this discipline in China's banking industry, though recruitment of any business anthropologist by the CFBs is still viewed as a pre-mature human resource practice. However, the researcher has not ignored this possible change in banking practices, given the growth of business anthropology in China. Though the research was not designed to investigate the impact of business anthropology on practice of guanxi in RM activities of the Relationship Managers of CFBs, it has already evoked interest in terms of future studies.

\section{Ethnography as a Research Method}

"Ethnography is a process of describing a culture in subjective ways that stem from the feelings and actions of informants who are functioning members of the group being investigated." (Tian et al., 2013). For anthropological research, researchers usually conduct their studies through observation, informal and structured interviews, questionnaires and focus groups. In this research, qualitative approach was used since the nature of guanxi is such that it cannot be quantified or measured quantitatively. In addition, the research was conducted by using semi-structured and in-depth interviews with ten Relationship Managers of the CFBs in Shanghai. Semi-structured interviews provide flexibility to interviewees when expressing their opinions since open-ended questions fit into the topic of guanxi which is a very complex issue. Indepth interviews are needed as the complications of questions do not allow interviewers to respond with a simple "yes" or "no" answer. The research is a typical example of ethnographic method as endorsed by the discipline of business anthropology.

\section{Guanxi in Corporate Culture and Cross-cultural Context}

Gwynne (2003, cited in Tian, 2010, p. 72-73; Tian et al., 2013, p. 37) stated that "any cultural anthropologist who is going to unknot and make explicable the culture of a small-scale society will have several different models to follow" and "each of these models provides a different means for conceiving 
and investigating the culture of a group of people who are bonded together by the same shared common values. In China, guanxi is a Chinese concept that stemmed from Confucius' social hierarchical theory which is referred to as the Chinese " $W u$ Lun" meaning five relationship hierarchies in the traditional Chinese society: ruler-subject, father-son, husband-wife, brother-brother and friend-friend ( $\mathrm{Su}$ et al., 2003). The conception of guanxi comes from Confucianism emphasizing personal relationship, loyalty, harmony, order and authority (Zhang and Zhang, 2006). Guanxi is deeply tied to the Confucian heritage of the Chinese people and is entrenched in the way of life of the Chinese. As mentioned in the Section of "Guanxi and Its Roles in Business", guanxi is a complex issue involving social, behavioural and human elements existing in China's banking industry. Tian (2013b) claimed "self-ownership", "renqing", "mianzi" and "guanxi" as values in China's society with association of business anthropology. Such concepts are also discussed in his book titled "Chinese-Canadians, Canadian-Chinese: Coping and Adapting in North America" (Tian, 1999).

On the other hand, RM, which is very similar to guanxi, is a Western concept. Foreign companies including the CFBs are practicing RM in China and thus creating a cross-cultural problem in respect of cultural differences between companies domiciled in Western countries but operating in China. To help smoothly practice guanxi in CFBs, business anthropologists should be employed. They should have the ability to "penetrate" corporate cultures and to elicit not only formal but also informal knowledge from them. The CFBs may also consider employing cultural anthropologists who know both the Chinese concept of guanxi and the Western concept of RM to help integrate the two different concepts for use by CFBs. On the other hand, the Relationship Managers of CFBs may draw support from the global model of Geert Hofstede who is the best known cross-cultural communications specialist. His work has given rise to the "four-dimensions of culture model" comprising of power distance, individualism-collectivism, uncertainty avoidance, and masculinity (Hofstede, 1980, 1991). To help minimize cross-cultural problems in integrating the Chinese concept of guanxi into the Western concept of RM, CFBs may consider "adding one more dimension into the Hofstede model, called Confucian dynamism with the special intention for differentiating Chinese from Western cultural values" (Fmery and Tian, 2003).

\section{Business Performance of CFBs versus Business Anthropology}

Business anthropologists can help companies to improve business performance by reviewing their corporate cultures, product design and development, marketing and consumer behaviour. Business anthropologists can also make contributions to other areas such as international business, human resources management and operations. In short, contributions that business anthropologists can make in the real world are unlimited. Besides, ethnographies have been increasingly used in the business world. Together with the areas mentioned above, business anthropologists can help companies to improve business performance and profitability.

Going back to the research findings, it is hard to draw conclusion whether the DCBs have outperformed the CFBs because of greater reliance on guanxi with their customers and the Chinese government. However, findings have confirmed that guanxi is still important for doing business in China despite its role having been eroded by reforms of economy and banking/finance systems in which competitive advantages and competencies of a bank override guanxi. Integration of guanxi into the RM activities of CFBs is considered an effective way to assist CFBs to improve their business performance in China. As this integration involves changes or modifications of the operations, marketing, management and corporate culture, business anthropologists can work together with cultural anthropologists by lending the CFBs a helping hand with the integration of guanxi into the RM practices of the CFBs.

\section{RECOMMENDATION FOR FURTHER RESEARCH}

The first issue identified for further research is the relationship between guanxi and business performance of banks in China. Some elements of the literature have indicated "no consensus" on the relationship. The second issue relating to the impact of guanxi on the CFBs could not be definitely confirmed, and it is still unknown whether the DCBs with high guanxi outperform the CFBs with low 
guanxi, or whether a lack of guanxi undermines business performance of the CFBs. The third issue is the relationship between guanxi and Western theories. Research on their interrelationships and interactions is very limited and there has been no study on impact of such relationships on the CFBs. In addition, given the importance of business anthropology, it is recommended for the CFBs to conduct research in relation to the impact of business anthropology on the integration of guanxi into their RM activities.

\section{CONCLUSION}

This research aimed at studying guanxi in RM activities of the CFBs. It is mainly of an exploratory nature, and has determined that there should be more in-depth discoveries concerning guanxi in marketing and operations of the CFBs. So far as the findings are concerned, there is no consensus on important implications of guanxi in China's banking sector but, without guanxi, Relationship Managers would find it difficult to solicit business and maintain rapport with customers. There are still many unanswered questions in respect of application of guanxi to RM activities of the CFBs. Specifically, the CFBs need to (1) study the effect of guanxi on their businesses and operations; and (2) understand the relationship between guanxi and business performance. These issues are more complex than indicated in the literature, thus setting a foundation for further research by managements and Relationship Managers together with business anthropologists and/or cultural anthropologists.

\section{REFERENCES}

Ai, J. (2006). Guanxi Networks in China: Its Importance and Future Trends. China \& World Economy, 14(5), pp. 105-118.

Alston, J.P. (1989). Wa, Guanxi, and Inhwa: Managerial Principles in Japan, China, and Korea. Business Horizon, March, pp. 26-31.

Arias, J.T.G. (1998). A relationship marketing approach to guanxi. European Journal of Marketing, 32(1/2), pp. 145-156.

Berry, L.L. (1983). Relationship Marketing, in Berry, L.L., Shostack, G.L. and Upsay, G.D. (eds), Emerging Perspectives on Service Marketing, Chicago, IL: American Marketing Association, pp. $25-8$.

Blau, P.M. (1964). Exchange and power in social life. New York, J. Wiley.

Braendle, U.C., Gasser, T., \& Null, J. (2005). Corporate Governance in China - Is Economic Growth Potential Hindered by Guanxi? Business and Society Review, 110(4), pp. 389-405.

Buckley, P.J., Clegg, J., \& Tan, H. (2006). Cultural awareness in knowledge transfer to China - The role of guanxi and mianzi. Journal of World Business, 41, pp. 275-288.

Butterfield, F. (1983). China: Alive in Bitter Sea. Coronet Books, NY.

Central Intelligence Agency (2010). The World Fact Book. Retrieved in March, 2013 from https://www.cia.gov/library/publication/the-world-factbook/geos/ch.html.

Chapman, M. (1997). Social Anthropology, Business Studies, and Cultural issues. International Studies of Management \& Organization, 26, 4.

Chen, S. \& Layton, R. (2003). Market orientation and guanxi in Chinese business enterprises - substitutes or complements? ANZMAC 2003 Conference Proceedings Adelaide, 1-3 December 2003, Market Orientation and Relationship Marketing Track, pp. 1217-1224.

Chen, X.P. and Chen C.C. (2004). On the Intricacies of the Chinese Guanxi. Asia Pacific Journal of Management, 21(3), pp. 305-324.

Cheng, L.W. (2007). Guanxi vs. relationship marketing: Exploring underlying differences. Industrial Marketing Management, 36, pp. 81-86.

Christopher, M. (1996). From brand values to customer value. Journal of Marketing Practice, 2(1), pp.5556.

Cropanzano, R. and Mitchell, M. (2005). Social Exchange Theory: An Interdisciplinary Review. Journal of Management, 31(6), pp. 874-900. 
Davies, H., Leung, T.K.P., Luk, S.T.K., \& Wong, Y.H. (1995). The Benefits of Guanxi: The Value of Relationships in Developing the Chinese Market. Industrial Marketing Management, 24(3), pp. 207-214.

Dunfee, T.W., \& Warren, D.E. (2001). Is Guanxi Ethical? A Normative Analysis of Doing Business in China. Journal of Business Ethics, 32, pp. 191-204.

Egan, J. (2004). Relationship Marketing: Exploring Relational Strategies in Marketing (2nd Ed.). Prentice Hall.

Emerson, R.M. (1976). Social exchange theory. Annual Review of Sociology, 2, pp. 335-362.

Fan, Y. (2002). Questioning guanxi: definition, classification and implications. International Business Review, 11, pp. 543-561.

Fernandez, J.A., \& Underwood, L. (2006). China CEO: Voices of Experience From 20 International Business Leaders. John Wiley \& Sons.

Ferraro, G.P. (2006). The Cultural Dimension of International Business, 5th Ed., Upper Saddle River, NJ: Pearson Prentice Hall.

Fisher, C. (2012). Editorial Commentary: China's Future in the World Marketplace. International Journal of China Marketing, 2(20), pp. 11-23.

Fock, H.K.Y., \& Woo, K.S. (1998). The China Market: Strategic Implications of Guanxi. Business Strategy Review, 9(3), pp. 33-43.

Geddie, M.W., DeFranco, A.L. \& Geddie, M.F. (2002). From Guanxi to customer relationship marketing: how the constructs of Guanxi can strengthen CRM in the hospitality industry. Journal of Hospitality and Tourism Marketing, 13(3), pp. 19-33.

Geddie, M.W., DeFranco, A.L., \& Geddie, M.F. (2005). A comparison of relationship marketing and Guanxi: Its implications for the hospitality industry. International Journal of Contemporary Hospitality Management, 17(7), pp. 614-632.

Gilbert, D., \& Tsao, J. (2000). Exploring Chinese cultural influences and hospitality marketing relationships. International Journal of Contemporary Hospitality Management, 12(1), pp. 45-53.

Gronroos, C. (1996). Relationship marketing: strategic and tactical implications. Management Decision, 34(3), pp. 5-14.

Hall, E. (1959). The silent language. Greenwich, England: Fawcett Publications.

Hall, E. (1960). The silent language in oversea business. Harvard Business Review, May-June, pp. 87-96.

Hammond, S.C. and Glenn, L.M. (2004). The ancient practice of Chinese social networking: Guanxi and social network theory, E:CO Special Double Issue, 6(1-2), pp. 24-31.

Harrell, S. ed. (2001). Perspectives on the Yi of Southwest China. Berkeley: Univ. Calif. Press.

Hofstede, G. (1980). Culture's Consequences: International Differences in Work-Related Value. Beverly Hills, CA: Sage Publications.

Hofstede, G. (1991). Cultures and Organizations: Software of the Mind. London: McGraw-Hill Book Company.

Jordan, A. (2002). Business anthropology. Prospect Heights, IL: Waveland Press.

Jordan, A. (2010). The Importance of Business Anthropology: Its Unique Contributions. International Journal of Business Anthropology, 1(1): 3-14.

Kasabov, E. (2007). Towards a contingent, empirically validated, and power cognizant relationship marketing. European Journal of Marketing, 41(1/2), pp.94-120.

Kotler, P. (2010). The Importance of China Marketing. Journal of Business Anthropology, 1(1), pp. 14-16.

Lam, D., \& Lin, X. (2003). Guanxi and Word-of-Mouth. ANZMAC 2003 Conference Proceedings Adelaide 1-3 December 2003. Marketing in International and Cross-Cultural Environments Track.

Lillis, M. and Tian, R. (2009). Cross-Cultural Communication and Emotional Intelligence. Marketing Intelligence \& Planning, 27(3), pp. 428-438.

Lu, L.T. (2012). Guanxi and Renqing: The Roles of Two Cultural Norms in Chinese Business. International Journal of Management, 29(2), Part 1, pp. 466-475.

Luo, Y., \& Chen, M. (1997). Does guanxi influence firm performance? Asia Pacific Journal of Management, 14, pp. 1-16. 
Millington, A., Eberhardt, M., \& Wilkinson, B. (2005). Gift Giving, Guanxi and Illicit Payments in Buyer-Supplier Relationships in China: Analysing the Experience of UK Companies. Journal of Business Ethics, 57(3), pp. 255-268.

Moeran, B. (2005). The Business of Ethnography: Strategic Exchanges, People and Organizations. Berg Publishers.

Morgan, R.M. and Hunt, S.D. (1994). The Commitment-Trust Theory of Relationship Marketing. Journal of Marketing, 58(July), pp. 20-38.

Noellert, M.Z. (2011). Debating Morals and the Discourse of Social Change in the Anthropology of Modern China (Book Review). Hong Kong University of Science and Technology. Anthropological Quarterly, Vol.84, No.3, pp.757-768.

Paliwoda, S.J. and Ryans, J.K. (2008). International Business vs. International Marketing. Cheltenham, UK: Edward Elgar Publishing.

Perrien, J. and Ricard, L. (1995). The Meaning of Marketing Relationship: A Pilot Study. Industrial Marketing Management, 24, pp.37-43.

Reice, H. (1993). Occupational Subcultures in the Workplace. Ithaca, NY: ILR Press.

Sin, L.Y.M. (1998). China Marketing. Chung Hua Book Store.

Sin, L.Y.M., Tse, A.C.B., Yau, O.H.M., Lee, J.S.Y., \& Chow, R. (2002). The effect of relationship marketing orientation on business performance in a service-oriented economy. Journal of Services Marketing, 16(7), pp. 656-676.

Standifird, S.S. (2006). Using Guanxi to Establish Corporate Reputation in China. Corporate Reputation Review, 9(3), pp. 171-178.

Su, C., \& Littlefield, E. (2001). Entering Guanxi: A Business Ethical Dilemma in Mainland China. Journal of Business Ethics, 33(3), pp. 199-210.

Su, C., Sirgy, M.J., \& Littlefield, J.E. (2003). Is Guanxi Orientation Bad, Ethically Speaking? A Study of Chinese Enterprises. Journal of Business Ethics, 44, pp. 303-312.

Tian, K. and Borges, L. (2011). Cross-Cultural Issues in Marketing Communications: An Anthropological Perspective of International Business. International Journal of China Marketing, 2(1), pp. 110-126.

Tian, R.G. (1999). Chinese-Canadians, Canadian-Chinese: Coping and Adapting in North America. The Edwin Mellen Press, Lewiston, NY.

Tian, R.G. (2009). Xinjiang and the Greater Central Asia Regional Economic Cooperation. Journal of Applied Business and Economics, 9(3): pp. 59-72.

Tian, R.G. (2010). The Unique Contributions and the Unique Methodologies: A Concise Overview of the Applications of Business Anthropology. International Journal of Business Anthropology, vol. 1(2), pp. 70-88.

Tian, R.G. (2011). Editorial Commentary: The Growth and Future of Business Anthropology. International Journal of Business Anthropology, vol. 2(2), pp. 11-13.

Tian, R.G. (2013a). Editorial Commentary: The Rise of Business Anthropology in China. International Journal of Business Anthropology, vol. 4(1), pp. 11-14.

Tian, R.G. (2013b) (田廣). Secret of Irregular Immigration of the Chinese to North America (中國人非現 則移民北美歷程揭秘). Commercial Book Store, Beijing (北京:商務印書館).

Tian, R.G., van Marrewijk, A. and Lillis, M.P. (2013). General Business Anthropology, 2nd Edition. North American Business Press.

Tian, R.G. and Wang, C.H. (2010). Cross-Cultural Customer Satisfaction at a Chinese Restaurant: The Implications to China Foodservice Marketing. International Journal of China Marketing, 1(1), pp. 60-72.

Tsang, W.K. (1998). Can guanxi be a source of sustained competitive advantages for doing business in China? The Academy of Management Executive, 12(2), pp. 64-73.

Tse, A.C.B., Sin, L.Y.M., Yau, O.H.M., Lee, J.S.Y., \& Chow, R. (2004). A firm's role in the marketplace and the relative importance of market orientation and relationship marketing. European Journal of Marketing, 38(9/10), pp. 1158-1172. 
Van Rij, J.B. (1996). Trends, symbols and brand power in global markets: The business anthropology approach. Strategy \& Leadership, pp. 18-24.

Walle, A. (2000). Rethinking marketing. Westport, CT: Quorum Books.

Walle, A. (2002). Exotic visions in marketing theory and practice. Westport, CT: Quorum Books.

Wan, A.Y.Y. and Ng, K.T.L. (2013). The Significance of Guanxi in Relationship Marketing: Perspectives of Foreign Banks in China. International Journal of China Marketing, vol. 3(2), pp. 72-99.

Wang, G.C., Liu, D. and Wang X.F. (2011). Effects of Perceived Organizational Support and Guanxi on Salesperson Performance: The Mediation of Customer Need Knowledge. Higher Education Press and Springer-Verlag, Front Bus. Res. China, 5(3), pp. 422-435.

Warren, D.E., Dunfee, T.W. and Li, N. (2004). Social Exchange in China: The Double-Edge Sword of Guanxi. Journal of Business Ethics, 55, pp. 355-372.

Wilson, J. and Brennan, R. (2010). Doing business in China: is the importance of guanxi diminishing? European Business Review, 22(6), pp. 652-665.

Wong, M.L. (2007). Guanxi and its role in business. Chinese Management Studies, 1(4), pp. 257-276.

Yang, F. (2011). The Importance of Guanxi to Multinational Companies in China. Asian Social Science, 7(7), pp. $163-168$

Yang, M.M. (1994). Gift, Favors and Banquets: The Art of Social Relationships in China. Ithaca, NY: Cornell University Press.

Yu, L.A., Chan, C., and Ireland, C. (2006). China's New Culture of Cool: Understanding the World's Fastest-Growing Market. Berkeley, CA: New Riders Press.

Zhang, Y., \& Zhang, Z. (2006). Guanxi and organizational dynamics in China: a link between individual and organizational levels. Journal of Business Ethics, 67, pp. 375-392. 